\title{
Race, Racism, and Inconvenient Truths
}

\section{J. Daryl Charles}

It was not by coincidence that three days after former Minneapolis police officer Derek Chauvin was sentenced to twenty-two years and six months for the "murder" of George Floyd the United Nations-sponsored Human Rights Council published the results of its year-long study on "racial discrimination." Those results were said to find racism to be "systemic," "structural," and “institutional” in nature. Under the title "Report of the United Nations High Commissioner for Human Rights" and published on June 1, 2021, ${ }^{1}$ the report claims to represent a "worldwide mobilization of people calling for racial justice."2

In its forty-third session a year earlier and prompted by a purported “worldwide groundswell," the Human Rights Council held an "urgent debate” on "current racially inspired human rights violations, systemic racism, police brutality and violence against peaceful protests." ${ }^{3}$ This debate produced a "Resolution” adopted by the Human Rights Council that was published on June 30, 2020, under the designation "Promotion and protection of the human rights and fundamental freedoms of Africans and people of African descent against excessive use of force and other human rights violations by law enforcement officers."

The Human Rights Council's report published in early June of this year begins as follows: “The murder of George Floyd on 25 May 2020 in Minnesota, United States of America, the mass protests that ensued in many countries[,] and the momentous verdict against one responsible law enforcement official represent a seminal point in the fight against racism." ${ }^{5}$ The focus of the report mirrors the assumption of broad-based-i.e., "systemic" and "structural"-

\footnotetext{
The report can be accessed at undocs.org/A/HRC/47/53.

UN Report, section 1, paragraph 2, page 4.

Ibid.

Accessible at undocs.org/A/HRC/RES/43/1.

UN Report, section1, paragraph 1, page 1.
}

J. Daryl Charles is the Acton Institute Affiliated Scholar in Theology and Ethics; dcharles@acton.org. 
racism aimed at "Africans and people of African descent."6 This "systemic" evil, according to the report, often "manifests itself in pervasive racial stereotypes, prejudice and bias and is frequently rooted in histories and legacies of enslavement, the transatlantic trade in enslaved Africans[,] and in colonialism."7

Following its "introduction and methodology," the report consists of four principal parts:

1. Reversing cultures of denial, dismantling systemic racism and accelerating the pace of action.

2. Ending impunity for human rights violations by law enforcement officials and closing trust deficits.

3. Ensuring that the voices of people of African descent and those who stand up against racism are heard and that their concerns are acted upon.

4. Confronting legacies, including through accountability and redress.

Prominent features of the report are telling. Frequently throughout there is reference to "States" (i.e., nations), yet the focus, from beginning to end, is the United States, with a secondary concern for European nations (to which, strangely, most immigrants and victims of human rights violations in Asia and Africa flee when seeking asylum). Curiously absent is any mention of terror and atrocity in Asia (whether in North Korea, China, Russia, Southeast Asia, India, or Myanmar). Neither is a single word in the report devoted to the persecution of millions by Islamist regimes in the Middle East and Asia (whether Iran, Afghanistan, Turkey, Egypt, Syria, Lebanon, or Yemen, where terrorist associations operate throughout). Nor does the report address tribalism and atrocity in continental Africa (whether the horn of Africa, Nigeria, or central Africa where genocide has been occurring since 1994.) For reasons known only to the council, the UN's "High Commissioner for Human Rights" is fixated on Minneapolis, Minnesota, and George Floyd, not on truly breathtaking human rights violations around the globe.

In addition to the aforementioned oversights, another gaping omission strikes the average reader of the report: the fact of disproportionate black crime in America as the most obvious cause of black engagement with law enforcement in high risk situations. Despite immense media coverage of the

6 Ibid., I.9. (5). This language pervades the entire report.

7 Ibid. 
Floyd case and the prodigious lengths to which journalists have gone to tie the event to "systemic" police racism, few have acknowledged Floyd's own criminal history or the fact that prosecutors did not charge the offending officer Derek Chauvin with racial discrimination. ${ }^{8}$ When investigating black interaction with police and the criminal justice system, it is surely worth noting that no other demographic group in the U.S. suffers from such high-risk intraracial behaviors, including not only high crime rates but family decomposition and out-ofwedlock births.

Another gaping omission in the UN's 2021 report should give us pause. I refer here to the fact of notable progress in race relations in England and the U.S. over the last two centuries. There is no mention of Western abolitionism from the outset of the slave trade or the individuals involved in defeating slavery. These include historical figures such as the converted slaver (and Christian hymn-writer) John Newton, John Wesley, William Pitt, Thomas Clarkson, and the Quakers of the sixteenth and seventeenth centuries, who worked in opposition to the cultural Zeitgeist. Nor is there any mention of William Wilberforce, who worked tirelessly in the British Parliament for several decades in the late eighteenth and early nineteenth centuries to abolish slavery and the slave trade. And why is there no mention of iconic individuals such as Harriet Beecher Stowe and Harriet Tubman, not to mention the more recent figure of Martin Luther King, Jr.? Where else in the world does one find such voices and continuous incremental progress?

Most egregiously, there is no mention in the report of the fact that race relations in America have come a long way since the day of Frederick Douglass and Abraham Lincoln. The civil rights movement of the 1960s put a legal end to segregation, and affirmative action has driven government programs, business and industry, higher education, and the media in unprecedented ways. Economic distinctions in the labor force between whites and blacks have nearly disappeared. Racial intermarriage, based on recent data from the Pew Research Center, is growing more prevalent in the U.S., with four-in-ten adults saying that it is a good thing. ${ }^{9}$ And in two elections a black man was elected as the U.S.

8 In the decade 1997-2007, according to court records of Harris County, Houston, where Floyd lived for much of his life before moving to Minneapolis in 2014, he was arrested nine times, several times related to the distribution of cocaine. In 2007, Floyd was charged with armed robbery in a home invasion, which resulted in a plea deal and sentencing of five years in prison.

9 "Public Views on Intermarriage," Pew Research Center, May 18, 2017, https://www.pewsocialtrends. org/2017/05/18/2-public-views-on-intermarriage/. 
President. These, most assuredly, are not signs of a society steeped in racial tyranny.

But let us return, for a moment, to the matter of black crime in the U.S. as well as the 2021 report's focus on what the Human Rights Council considers to be the pressing issue in race relations, namely, "police brutality.” This requires, however, that we take one step back and soberly consider the evidence before us. One category of very damning evidence that, in truth, not all black lives matter concerns violent crime in the U.S. And it is here that both blacks and whites take aim with deadly precision at "white supremacist" culture, refusing to acknowledge the reasons for the proliferation of predatory (and fatherless) black males. Consider, just for starters, these realities: (1) black homicide victim rates are roughly six times what they are among whites; (2) blacks are almost half of all homicide victims and over half of offenders; (3) blacks comprise roughly 45 percent of all felony murder victims and 60 percent of the offenders, even though they comprise only 13 percent of the national population; and (4) blacks account for roughly two-thirds of all drug-related homicides, compared with roughly one-third among whites. ${ }^{10}$

And this does not even begin to take into consideration the matter of black incarceration, a phenomenon that cannot be explained merely by citing "systemic injustice," “white supremacy,” or “white oppression.” No present-day activists, whether black or white, seem willing to raise the question of black self-responsibility or the matter of "civil society" and the need to protect the common good. Should predatory black males be left off the hook, whatever the crime, simply because of race? And what is the alternative?

In truth, American society is witness to an assault on black lives, but that assault has nothing to do with white racism, "white supremacy," or "police brutality." Rather, it has its roots chiefly in problems within the black community that appear to be endemic-or, shall we say, pandemic. Tragically, much of American culture in the present day is willing to embrace a false narrative on race. And perhaps this is where the UN's "High Commissioner of Human Rights" Michelle Bachelet Jeria received much of her impetus to investigate "systemic" and "structural" racism.

A grossly inaccurate portrait of black victimization concerns supposed racist application of force by police and law enforcement agents. The UN

10 For a good summary of crime data see Barry Latzer, "The Facts on Race, Crime, and Policing in America," Law \& Liberty, June 18, 2020. 
report's wildly exaggerated portrait, which adopts a wholly false stereotype, surely needs to be challenged. Mainstream media outlets and those in the academy surely will not help us in this regard. What does the best research indicate?

Contributing to the most recent data of note is a study by David J. Johnson et al., "Officer Characteristics and Racial Disparities in Fatal Officer-Involved Shootings," published in July of 2019 in the Proceedings of the National Academy of Sciences. Motivation for this study, which followed on the heels of several high-profile police shootings of black males, was said by the authors to be a "widespread concern about racial disparities in fatal officer-involved shootings and that these disparities reflect discrimination by White officers."

The study was designed to create "a comprehensive database of officers involved in fatal shootings during 2015 " with a view to "predict victim race from civilian, officer, and county characteristics." Contributing to the breadth of this investigation was the obtaining of officer information from "all 684 police departments who [sic] had officers involved in a fatal shooting” through January of 2016. Summarizing the results of this noteworthy study, the authors observe: "We did not find evidence for anti-Black or anti-Hispanic disparity in police use of force across all shootings, and, if anything, found anti-White disparities when controlling for race-specific crime.” Correlatively, white officers were "not more likely to shoot minority civilians" than non-white officers. In addition, black and Hispanic officers (compared with white officers) were found to be more likely to fatally shoot black and Hispanic civilians.

A 2016 econometric study done by a black professor of economics at Harvard, Roland G. Fryer, Jr., confirms these findings. Under the title of "An Empirical Analysis of Racial Differences in Police Use of Force," which appeared in the Journal of Political Economy, this study was conducted jointly with the National Bureau of Economic Research.

According to the study's findings, in the context of non-lethal uses of force, even when blacks and Hispanics "are more than fifty percent more likely to experience some form of force in interactions with police," on the most extreme use of force-i.e., officer-involved shootings-the study found "no racial differences in either the raw data or when contextual factors are taken into account."

One of the few national studies done to establish whether racial disparities were present in officer-involving shootings involving white police officers was initiated in 2015 and subsequently published in 2019 in the journal Public Administration Review, under the title "Do White Law Enforcement Officers 
Target Minority Suspects?” This particular study found that white officers were no more likely to fatally shoot black or Hispanic civilians than non-white officers, although the findings were based on a relatively small subset (19-23 percent) of all fatal shootings nationwide. The findings of this study comport with those of a 2018 study published in the Journal of Crime and Justice-“Disparity Does Not Mean Bias: Making Sense of Observed Racial Disparities in Fatal Officer-Involved Shootings with Multiple Benchmarks.” The results of that study, based on the benchmarks of "population, police-citizen interactions, or total arrests," were that "black citizens appear less likely to be fatally shot by police officers."

As it turns out, the myth of "police brutality" is precisely that-a myth.

It is a curious-and evidently quite forgettable-fact that the only location on earth in which redemptive efforts in the sphere of racial relations has occurred in the last two centuries has been in the West, and specifically in the U.K. and the U.S. William Wilberforce's legacy, which resulted from tireless efforts in the British Parliament stretching over decades to eradicate slavery, need not get in the way of twenty-first-century social activism. The fact that nowhere else in the world outside of the West can one find the impetus for countering racism and slavery is, in the end, of no consequence. The UN's report is final and authoritative: "We could not find a single example of a state that has fully reckoned with the past or comprehensively accounted for the impacts of the lives of people of African descent today."

Given her predilections, the "United Nations High Commissioner for Human Rights” would do well to read Thomas Sowell, whose work in the sphere of race and culture worldwide is unparalleled. ${ }^{11}$ And should the Commissioner read Sowell and honestly embrace his insights, she would be challenged to forsake her social activism, acknowledge that racism is universal, and discover the crucial role that culture and behavior play as determinants of individual and group well-being.

She might also give up her preoccupation with Minneapolis in May of 2020-an event that both raised to sainthood a menace to society and undermined law and order for many years to come.

11 Comments by the Human Rights Council's "High Commissioner" following the release of the report can be found at https://www.ohchr.org/EN/NewsEvents/Pages/DisplayNews.aspx?NewsID=27218\&Lan$g \mid D=E$. 